\title{
Chemical food safety hazards of insects reared for food and feed
}

\author{
A.M. Meyer, N. Meijer, E.F. Hoek-van den Hil and H.J. van der Fels-Klerx* \\ Wageningen Food Safety Research, Akkermaalsbos 2, 6708 WB Wageningen, the Netherlands; ine.vanderfels@wur.nl
}

Received: 23 July 2020 / Accepted: 1 October 2020

(c) 2021 Wageningen Academic Publishers

OPEN ACCESS CC) REVIEW ARTICLE

\begin{abstract}
Insects are a promising future source of sustainable proteins within a circular economy. Proving the safety of insects for food and feed is necessary prior to supplying them to the market. This literature review provides a state-of-theart overview of the chemical food safety hazards for insects reared for food and feed, focusing mainly on transfer of contaminants from the substrate. Contaminants covered are: heavy metals, dioxins and polychlorinated biphenyls, polyaromatic hydrocarbons, pesticides, veterinary drugs, mycotoxins, and plant toxins. The twelve insect species reported as having the largest potential as feed and food in the EU are included. Transfer and bioaccumulation of contaminants depend on the chemical, insect species, life stage, and source of contaminant (spiked vs natural), as well as the particular substrate and rearing conditions. The heavy metals lead, arsenic, mercury, and cadmium can accumulate, whereas mycotoxins and polycyclic aromatic hydrocarbons (PAHs) seem not to accumulate. Mycotoxins and veterinary drugs could be degraded by insects; their metabolic routes need to be further investigated. Data are generally limited, but in particular for PAHs, plant toxins, and dioxins and dioxin-like polychlorinated biphenyls. Further research on chemical safety of different edible insects is therefore warranted.
\end{abstract}

Keywords: contaminants, edible insects, exposure, literature review

\section{Introduction}

Before insects are put on the European market as an ingredient for feed and food, they should be proven to be safe for livestock, pets, and humans. Insects can be efficiently reared with a minimal amount of resources on a wide range of substrates, such as organic side streams, at a high conversion rate (Van Huis et al., 2013; Varelas, 2019). Insects emit lower greenhouse gasses and ammonia in comparison to conventional production animals (Oonincx et al., 2011). Furthermore, insects contain high quality protein, amino acids, and vitamins for animal and human health (Rumpold and Schlüter, 2015). Insects can contain high fat fractions, including omega-3 fatty acids, that are essential for fish and human nutrition (Van Huis et al., 2013). In Europe, insects are seen as a novel source of protein for feed and food production, that could help in producing enough food and feed for the growing European population (Bordiean et al., 2020). The use of insect protein can partly replace the heavy import of protein sources from non-European areas.
In the European Union (EU), under Regulation (EC) No $142 / 2011$, seven species of insects are currently legally allowed to be fed to aquaculture animals (EC, 2011a). In principle, there is no restriction on which insect species are allowed to be used in pet food (Regulation (EC) No $1069 / 2009$ ) and feed for fur animals (Regulation (EC) No 999/2001) (EC, 2001, 2009). To produce and market insects for food, the producer should submit a dossier to the European Commission requesting for approval since insects were not consumed in Europe before the $15^{\text {th }}$ of May 1997 (Regulation (EU) No 2015/2283) (EC, 2015a). Currently, several of the dossiers are under evaluation of EFSA (EC, 2015b). As a part of the dossier, evidence of the safety of insects for human consumption should be included. In particular, the possible presence of food safety hazards, including physical, microbiological, and chemical hazards, should not cause any short- or longterm human health problems. Information on the safety of insects for feed and food have been collected and brought together initially by EFSA (2015) and later in an extensive literature review (Van der Fels-Klerx et al., 2018). Since then, additional experiments have been performed to fill 
the identified data gaps on the chemical safety of edible insects.

The current review aims to present an updated overview of the potential chemical food safety hazards that could be present in insects reared for feed and food. It is focused on contamination of insects by their exposure to chemicals in the substrates in the rearing phase, because of: (1) the relative importance of this contamination route for the presence of chemicals in harvested insects; (2) limited available data on effects of processing on chemicals; and (3) the relevance of food safety control at the upstream stages of the supply chain. Chemicals are generally stable and difficult to remove or reduce by processing steps, like cooking, further downstream the chain. Therefore, if contaminants do accumulate in insects, this could potentially pose a problem, either within the fat or protein fractions of the insects or the insect products themselves, through the processing, distribution, and consumption stages (Mutungi et al., 2019).

\section{Materials and methods}

The comprehensive review by Van der Fels-Klerx et al. (2018) was completed in the beginning of 2017. Therefore, additional recent published studies were searched for in the current study. The review used the bibliographic databases CAB Abstracts, Web of Science, and Scopus to collect peer-reviewed papers written in the English language and published in the time period 1 January 2017 to 1 September 2020. In the case of limited data available on a particular contaminant group, earlier published papers were also included to provide a complete overview.

The literature search focused on chemical hazards in insects reared for food and/or feed, thus excluding insects harvested from the wild. Species covered included those considered by EFSA as having the largest potential to be used as food and feed in the EU, being: black soldier fly (Hermetia illucens) and common housefly (Musca domestica); yellow mealworm (Tenebrio molitor), lesser mealworm (Alphitobius diaperinus), and giant mealworm (Zophobas atratus); house cricket (Acheta domesticus), banded cricket (Gryllodes sigillatus); greater wax moth (Galleria mellonella), lesser wax moth (Achroia grisella), silkworm (Bombyx mori), African migratory locust (Locusta migratora migratorioides), and American grasshopper (Schistocerca americana) (EFSA, 2015). Particular attention was given to bioaccumulation of chemicals in the larvae and/or cricket species from the substrate. All types of substrates were considered, also including the ones not currently legally allowed in the EU. Results are presented in the next sections for each of the main group of chemical contaminants separately, including: heavy metals, dioxins and polychlorinated biphenyls, polyaromatic hydrocarbons, pesticides, veterinary drugs, mycotoxins, and plant toxins.

\section{Heavy metals}

Possible bioaccumulation of several heavy metals has been investigated in various insect exposure studies held under controlled conditions. The focus of these studies was on the heavy metals currently regulated in feed and food in the EU, being; cadmium $(\mathrm{Cd})$, lead $(\mathrm{Pb})$, mercury $(\mathrm{Hg})$, and arsenic (As) (Regulation (EC) No 1881/2006) (EC, 2006a). Table 1 summarises the results from the recent exposure studies involving a substrate contaminated by the four mentioned heavy metals with $H$. illucens and T. molitor larvae. Results show that the heavy metal accumulation in insects depends on the type of heavy metal, the insect species, the substrate and, possibly the packaging material of the substrate (Van der Fels-Klerx et al., 2020). For example, bioaccumulation factor (BAF) of $\mathrm{Pb}$ in $T$. molitor fed $100 \%$ organic wheat flour was 34 , whereas it was 6.1 when fed $75 \%$ organic wheat meal and $25 \%$ organic olive-pomace (Truzzi et al., 2019). The authors speculated that this high accumulation may have been due to elevated levels of $\mathrm{Pb}$ in the carrots that had been provided as a water source to all treatments; but this had not been verified by (Truzzi et al., 2019). In addition, $H$. illucens fed vegetable-based substrate in a carton had a BAF of 20.4 for $\mathrm{Cd}$, but BAF for this metal was 7 when H. illucens were fed the same vegetable-based substrate but in a plastic container (Van der Fels-Klerx et al., 2020). Furthermore, H. illucens fed on seaweed-enriched media accumulated $\mathrm{Cd}, \mathrm{Pb}, \mathrm{Hg}$, and As (Biancarosa et al., 2018). The two recent studies that investigated As in H. illucens reported BAF $<1$ (Table 1). Possible As accumulation in T. molitor was studied in only one recent study reporting a BAF of 1.1, confirming results from (Van der Fels-Klerx et al., 2016) who reported a BAF of 1.4-2.6 in T. molitor larvae.

Gao and co-authors (Gao et al., 2019a) fed M. domestica with food waste including different percentages of dish waste, and reported a lower concentration of $\mathrm{Cd}$ in the larvae compared to other elements tested, which is congruous with previous reports (Jiang et al., 2017). Currently, not all combinations of the four regulated heavy metals and the insect species considered in this review have been investigated. Therefore, species not investigated yet, such as $A$. diaperinus and $A$. domesticus among others, should be considered in further studies.

\section{Dioxins/PCBs/PAHs}

Dioxins (and furans - PCDD/F) and dioxin-like polychlorinated biphenyls (dl-PCBs) are chemicals currently banned under the Stockholm Convention due to well documented toxic effects throughout the food chain. However, local contamination of these chemicals still exists in the environment, predominantly in soils, sediment, and air, which may result in contamination of crops used for feed or food (Pius et al., 2019). As insects are being reared on a variety of waste streams, these lipophilic pollutants are 
Table 1. Bioaccumulation of heavy metals in insect larvae.

\begin{tabular}{|c|c|c|c|}
\hline Heavy metal & Bioaccumulation factor & Species & Reference \\
\hline \multirow[t]{4}{*}{ Arsenic } & $0.8 \pm 0.1$ & Hermetia illucens & Proc et al. (2020) \\
\hline & $0.5-1.1$ & H. illucens & Schmitt et al. (2019) \\
\hline & $1.1 \pm 0.1$ & Tenebrio molitor & Truzzi et al. (2019) \\
\hline & $0.88-0.99$ & H. illucens & Truzzi et al. (2020) \\
\hline \multirow[t]{7}{*}{ Cadmium } & $9.1 \pm 1.4$ & H. illucens & Purschke et al. (2017) \\
\hline & $3.9 \pm 0.6$ & H. illucens & Proc et al. (2020) \\
\hline & $2.5 \pm 0.1$ & H. illucens & Schmitt et al. (2019) \\
\hline & $7-20.4$ & H. illucens & Van der Fels-Klerx et al. (2020) \\
\hline & $0.8-1.7$ & T. molitor & Truzzi et al. (2019) \\
\hline & $1.8-2.5$ & T. molitor & Mlček et al. (2017) \\
\hline & $4.2-6.9$ & H. illucens & Truzzi et al. (2020) \\
\hline \multirow[t]{6}{*}{ Lead } & $2.3 \pm 0.3$ & H. illucens & Purschke et al. (2017) \\
\hline & $0.03 \pm 0.03$ & H. illucens & Proc et al. (2020) \\
\hline & $0.8 \pm 0.1$ & H. illucens & Schmitt et al. (2019) \\
\hline & $2.1-3.1$ & H. illucens & Van der Fels-Klerx et al. (2020) \\
\hline & $5.2-34$ & T. molitor & Truzzi et al. (2019) \\
\hline & $1.6-2.3$ & H. illucens & Truzzi et al. (2020) \\
\hline \multirow[t]{5}{*}{ Mercury } & 0.5 & H. illucens & Purschke et al. (2017) \\
\hline & $1.5 \pm 0.1$ & H. illucens & Proc et al. (2020) \\
\hline & $1.6 \pm 0.1$ & H. illucens & Schmitt et al. (2019) \\
\hline & $1.5-6.2$ & T. molitor & Truzzi et al. (2019) \\
\hline & $1.4-4.5$ & H. illucens & Truzzi et al. (2020) \\
\hline
\end{tabular}

being investigated for safe insect rearing. The concentration of dioxins and dl-PCBs may substantially concentrate in fat extracts of insects for food/feed. Dioxins and dl-PCBs concentrations were analysed in reared insects for feed, and reported to range from 0.23 to $0.63 \mathrm{ng}$ toxic equivalency factor (TEQ)/kg dry weight (Charlton et al., 2015). The authors noted that these figures are below the EC maximum allowed content in feed materials of animal origin (1.25 ng WHO-PCDD/ F-PCB-TEQ/kg, considering 88\% dry matter) (EC, 2006a). In addition, dioxins and dioxin-like PCBs were analysed in insects and insect products for food and feed. Concentrations ranged from 0.05-0.28 pg WHO-TEQ/g ww in the edible insects, which was two times higher than in the insect derived products, probably, due to dilution of other ingredients within the insect product (Poma et al., 2017). In a recent study in which $H$. illucens was fed on supermarket waste, larvae were analysed for dioxins and dl-PCBs (Van der Fels-Klerx et al., 2020). These treatments included substrates packaged in either plastic or carton and with or without meat. Concentrations of dioxins and dl-PCBs (WHO-2005PCDD/F-PCB-TEQ upper bound) were 0.2-0.3 ng TEQ/kg $\mathrm{dw}$ for the substrates, and 0.3-0.4 ng TEQ/kg dw for both the larvae and the residual materials. Concentrations of both the substrates and reared $H$. illucens larvae did not exceed current EC limits for these contaminant groups in feed materials. In the same study, concentrations of polycyclic aromatic hydrocarbons (PAHs) were also analysed.
Reported PAH16 (upper bound) concentrations were low, with levels in the substrates of $1.8-6.6 \mu \mathrm{g} / \mathrm{kg} \mathrm{dw}$, in the larvae of $1.9-2.1 \mu \mathrm{g} / \mathrm{kg} \mathrm{dw}$, and in the residues of $2.1-5.2 \mu \mathrm{g} / \mathrm{kg} \mathrm{dw}$ (Van der Fels-Klerx et al., 2020). PAHs are chemically stable compounds in the environment which can be formed after burning. Currently, there are no legal limits for the presence of PAHs in feed materials in Europe. However, since these compounds can be carcinogenic and DNA damaging, the concentration of PAHs in insects should be as low as possible. PAHs are increasingly found in vegetable based aquafeed materials and potentially in vegetable based waste streams (Berntssen et al., 2015).

Table 2 shows that dioxins and dl-PCBs as well as PAHs did not accumulate in $H$. illucens larvae, or only accumulated to very little extent, up to BAF of 2 for dioxins and dl-PCBs and up to 1.2 for PAHs in the various treatments (Van der Fels-Klerx et al., 2020).

Controlled experiments on possible accumulation of dioxins, dl-PCBs, and PAHs have not been identified for the other insect species under consideration of this review. Since these compounds are known to accumulate in fatty tissues of production animals, they should be investigated in future studies (Fries, 1995). Based on the results for H. illucens larvae, accumulation of dioxins and dl-PCBs is expected in other insect species used for food and feed. 
Table 2. Bioaccumulation of dioxins, dioxin-like polychlorinated biphenyls, and polycyclic aromatic hydrocarbons in Hermetia illucens larvae from supermarket returns (Van der Fels-Klerx et al., 2020).

\begin{tabular}{ll} 
Contaminant & Bioaccumulation factor \\
Dioxins (WHO2005-PCDD/F-TEQ (ub)) $)^{1,2}$ & $1.0-2.0$ \\
Sum of dioxins and dioxin-like PCBs & $1.0-2.0$ \\
$(\mathrm{WHO} 2005-\mathrm{PCDD} / \mathrm{F}-\mathrm{PCB}-\mathrm{TEQ}(\mathrm{ub}))^{1,2}$ & \\
PAH16 (ub) & $0.3-1.2$ \\
\hline${ }^{1}$ World Health Organization (WHO) toxic equivalency factor (TEQ). \\
${ }^{2}$ ub = upper bound value (limits of detection used per congener).
\end{tabular}

\section{Pesticides}

In literature on the effects of reared insects discussed in a previous review (Van der Fels-Klerx et al., 2018), it was largely concluded that tested pesticides did not accumulate in the considered species. These included azoxystrobin and propiconazole (Lalander et al., 2016), chlorpyrifos and chlorpyrifos-methyl, and pirimiphos-methyl (Purschke et al., 2017) in H. illucens larvae, and epoxiconazole (Lv et al., 2014), metalaxyl (Gao et al., 2014), benalaxyl (Gao et al., 2013), and mycolobutanil (Lv et al., 2013) in A. diaperinus larvae. In addition, Poma and co-authors (Poma et al., 2017) confirmed the presence of pirimiphos-methyl in Locusta migratoria and in some insect products including a Buggie burger. Recent literature on the effects of pesticides on insect species reared specifically for food or feed purposes is scarce. Available data suggest that accumulation is most likely not a food safety concern. However, for some pesticides, the presence of low concentrations of pesticides in the substrate, below the EC legal limit, may affect insect growth and survival (unpublished data). More research is needed to determine effects of a larger variety of pesticides that are commonly found in residues of feed materials used for rearing insects.

\section{Veterinary drugs}

There is only limited data available on the possible presence or accumulation of veterinary drug residues in edible insects. When insects are reared on manure (though currently not allowed in Europe), they could be exposed to residues of veterinary drugs. Furthermore, veterinary drugs may also be used during the rearing of insects to prevent infections. The use of antibiotics may, however, also affect the development of edible insects and the spread of antibiotic-resistant pathogens, which could outweigh the possible benefits of using antibiotics (Grau et al., 2017). Therefore, veterinary drugs could be used during insect rearing, however it is a challenge to find the optimal balance between limiting microbial growth and optimal growth and survival of the insects (Roeder et al., 2010).

Some studies investigated the ability of $H$. illucens larvae to reduce pharmaceuticals in the environment. Cai and co-authors (Cai et al., 2018) studied the mechanisms of tetracycline degradation by the intestinal microflora of $H$. illucens. Non-sterile substrates of moistened wheat bran were spiked with tetracycline in concentrations of 20 , 40 , and $80 \mathrm{mg} / \mathrm{kg} \mathrm{dw}$. It was shown that $H$. illucens could rapidly degrade tetracycline, which was due to the intestinal microbiota of the larvae. More than $75 \%$ of tetracycline was degraded at day 8 , while at day 12 the reduction was between $95-96 \%$. Several possible biodegradation products were identified in larval intestinal isolates (Cai et al., 2018). Another study (Lalander et al., 2016) showed that the halflife of the pharmaceuticals carbamazepine, roxithromycin, and trimethoprim, as spiked in the substrate, was shorter with $H$. illucens feeding off of the compost substrate and no bioaccumulation was detected in the larvae. Composting of organic waste by H. illucens larvae could, therefore, reduce the pharmaceuticals in the environment (Lalander et al., 2016). Biodegradation of antibiotics present in swine manure and chicken manure was also observed with $M$. domestica larvae. Concentrations of nine antibiotics, including tetracyclines, sulfonamides, and fluoroquinolones were clearly decreased during a six-day larvae manure vermicomposting process. The cumulative removal of oxytetracycline, chlortetracycline, and sulfadiazine was around 70\% (Zhang et al., 2014). The veterinary antibiotic monensin, a feed additive according to EU regulation (EC, 2020), which is widely used in broiler feed was also reduced in a 12-day vermicomposting experiment with $M$. domestica larvae. After four days, the concentration of monensin in the chicken manure was reduced by $95 \%$, while this reduction took twelve days for the control group. It was concluded that the reduction was due to monensin degrading bacteria in the gut of the larvae (Li et al., 2019).

In other studies, some residues of veterinary drugs were detected in edible insects (Table 3). Several insects intended for human or animal consumption including A. diaperinus, $H$. illucens, and $A$. domesticus were screened for the possible presence of 75 (veterinary) drugs, pesticides, and mycotoxins. The veterinary drugs salicylic acid and metoprolol were detected in the three insect species (1-3 $\mu \mathrm{g} / \mathrm{kg}$; De Paepe et al., 2019). Furthermore, it was shown that the antibiotic sulfonamide could affect the growth of H. illucens. Sulfonamide was spiked at concentrations of $0,0.1,1$, and $10 \mathrm{mg} / \mathrm{kg}$ in the substrate. Only the highest concentration of sulfonamide affected the survival of the larvae, resulting in $30 \%$ survival. The body weight and development of the larvae were also affected by sulfonamide. Sulfamonomethoxine, sulfamethoxazole, and sulfamethazine were not detected in the prepupae, while only sulfadiazine was detected with a treatment of 1 and 
$10 \mathrm{mg} / \mathrm{kg}$ (0.5-0.8 mg/100 prepupae). It was concluded that $H$. illucens larvae can be used to partly remove veterinary drugs from manure to protect the environment (Gao et al., 2019b).

From the limited data available, it can be concluded that residues of some veterinary drugs could be found in edible insects and could affect the larval growth, however, it has also been shown that veterinary drugs can be degraded by insects, possibly due to the gut microbiota. More research is needed on the effects of residues of specific veterinary drugs as present in potential substrates for insect rearing, in combination with the particular insect species reared on that substrate.

\section{Other environmental contaminants}

Poma and co-authors (Poma et al., 2019) investigated the contamination levels of a large variety of insect food products derived from different insect species, purchased from five European countries (Austria, France, UK, Belgium, and the Netherlands) and three Asian countries (P.R. China, Japan, and R. Korea). A variety of species belonging to six orders, being Orthoptera, Coleoptera, Lepidoptera, Hemiptera, Odonata, and Hymenoptera, were analysed. The list of targeted compounds consisted of 31 persistent organic pollutants (POPs), including: 20 polychlorinated biphenyls (PCBs) and 11 organochlorine compounds (OCPs); 11 halogenated flame retardants (HFRs), including 9 polybrominated diphenyl ethers (PBDEs) and 2 dechlorane plus (DPs); 18 plasticisers, including 7 legacy plasticisers (LPs), and 11 alternative plasticisers (APs); 17 phosphorous flame retardants (PFRs), including 12 legacy PFR, and 5 emerging PFRs (ePFRs); 8 LP biotransformation products
(LPs-BT), 11 AP biotransformation products (APs-BT), and 12 PFR biotransformation products (PFRs-BT). The authors concluded that contamination varied between insect species and products, nevertheless levels were generally low. They speculated that industrial post-harvesting handling and other ingredients may have contributed more to elevated contaminant levels in the insect products rather than the insects themselves. Bioaccumulation of contaminants was not investigated in this study.

\section{Mycotoxins}

Mycotoxins are secondary metabolites produced by certain fungal species, mostly from the genus Aspergillus spp., Fusarium spp., and Penicillium spp., that are toxic to animals and humans. Certain mycotoxins, such as aflatoxin $\mathrm{B}_{1}$ (AFB1), deoxynivalenol (DON), zearalenone (ZEN), ochratoxin A (OTA), and fumonisins (FB1, FB2, FG1, FG2), are known to pose threats to livestock and human health (Gashaw, 2016). Therefore, the presence of these mycotoxins in feed and/or food products has been regulated or guidance levels have been established in Europe (EC, 2006a,b, 2011b).

Possible accumulation of mycotoxins in insects has been investigated in several studies with spiked and naturally contaminated substrates from different feed materials and waste streams, and with different insect species. Results from these studies lead to a better understanding of mycotoxin uptake, transformation, and excretion by insects for feed and food (Leni et al., 2019). Results of recent studies showed that tolerance to mycotoxins varies, depending on insect species and mycotoxins. For example, H. illucens fed poultry feed spiked with AFB1 did not accumulate this toxin, and levels in the larvae were below the detection

Table 3. Possible accumulation of veterinary drugs in insect larvae.

\begin{tabular}{|c|c|c|c|}
\hline Veterinary drugs & Results / accumulation & Species & References \\
\hline Tetracycline & $\begin{array}{l}\text { Degradation in the substrate by microbiota } \\
\text { of } H \text {. illucens }\end{array}$ & Hermetia illucens & Cai et al. (2018) \\
\hline $\begin{array}{l}\text { Roxithromycin, trimethoprim, } \\
\text { and carbamazepine }\end{array}$ & $\begin{array}{l}\text { Degradation in the substrate; no accumulation } \\
\text { in the larvae }\end{array}$ & H. illucens & Lalander et al. (2016) \\
\hline $\begin{array}{l}\text { Tetracycline, oxytetracycline, } \\
\text { chlortetracycline, doxycycline, sulfadiazine, } \\
\text { norfloxacin, ofloxacin, ciprofloxacin, and } \\
\text { enrofloxacin }\end{array}$ & Degradation in the substrate & Musca domestica & Zhang et al. (2014) \\
\hline Monensin ${ }^{1}$ & Degradation in the substrate by the microbiota & M. domestica & Li et al. (2019) \\
\hline Salicylic acid, metoprolol & $\begin{array}{l}\text { Low levels found in insects intended for human or } \\
\text { animal consumption }\end{array}$ & $\begin{array}{l}\text { H. illucens, Alphitobius } \\
\text { diaperinus }\end{array}$ & De Paepe et al. (2019) \\
\hline Sulfonamide & $\begin{array}{l}\text { Sulfamonomethoxine, sulfamethoxazole, and } \\
\text { sulfamethazine were not detected, while only } \\
\text { sulfadiazine was detected in the prepupae }\end{array}$ & H. illucens & Gao et al. (2019b) \\
\hline
\end{tabular}


Table 4. Possible accumulation of mycotoxins in insect larvae.

\begin{tabular}{|c|c|c|c|c|}
\hline Mycotoxins & $\begin{array}{l}\text { Concentration in } \\
\text { substrate }(\mu \mathrm{g} / \mathrm{kg})\end{array}$ & $\begin{array}{l}\text { Concentration in } \\
\text { larvae }(\mu \mathrm{g} / \mathrm{kg})^{1}\end{array}$ & Species & References \\
\hline \multirow[t]{3}{*}{ Aflatoxin $B_{1}$} & 415 & $<\mathrm{LOD}^{2}, 10 \%$ legal limit ${ }^{3}$ & Hermetia illucens, Tenebrio molitor & Bosch et al. (2017) \\
\hline & 390 & $<\mathrm{LOQ}^{2,4}$ & H. illucens, Alphitobius diaperinus & Camenzuli et al. (2018) \\
\hline & 13 & $<L O D$ & H. illucens & Purschke et al. (2017) \\
\hline \multirow[t]{5}{*}{ Zearalenone } & $14.9-79.9$ & $<L O Q$ & T. molitor & Niermans et al. (2019) \\
\hline & & $<\mathrm{LOD}^{2}, 60^{3},<\mathrm{LOD}^{5}$ & H. illucens, T. molitor, Acheta domesticus & De Paepe et al. (2019) \\
\hline & 13,000 & $>\mathrm{LOQ}^{2},<\mathrm{LOQ}^{4}$ & H. illucens, A. diaperinus & Camenzuli et al. (2018) \\
\hline & 39 & $<L O D$ & H. illucens & Purschke et al. (2017) \\
\hline & 173 & $<L O D$ & T. molitor & Leni et al. (2019) \\
\hline \multirow[t]{4}{*}{ Deoxynivalenol } & 12,000 & $<131$ & T. molitor & Ochoa Sanabria et al. (2019) \\
\hline & 112,000 & $>\mathrm{LOQ}^{2},<\mathrm{LOQ}^{4}$ & H. illucens, A. diaperinus & Camenzuli et al. (2018) \\
\hline & 698 & $<L O D$ & H. illucens & Purschke et al. (2017) \\
\hline & $779^{2}, 1,207^{3}$ & $<\mathrm{LOD}^{2}, 726^{3}$ & H. illucens, T. molitor & Leni et al. (2019) \\
\hline \multirow[t]{2}{*}{ Ochratoxin A } & 1,700 & $>\mathrm{LOQ}^{2},<\mathrm{LOQ}^{4}$ & H. illucens, A. diaperinus & Camenzuli et al. (2018) \\
\hline & 130 & $<L O D$ & H. illucens & Purschke et al. (2017) \\
\hline Fumonisin $\mathrm{B}_{1}$ and $\mathrm{B}_{2}$ & $\begin{array}{l}573^{2}, 727^{3}, 441^{2} \\
294^{3}\end{array}$ & $\begin{array}{l}<\mathrm{LOD}^{2},<\mathrm{LOD}^{3}, \\
<\mathrm{LOD}^{2},<\mathrm{LOD}^{3}\end{array}$ & H. illucens, T. molitor & Leni et al. (2019) \\
\hline \multicolumn{5}{|c|}{${ }^{1} \mathrm{LL}=$ legal limit; $\mathrm{LOQ}=$ limit of quantification; $\mathrm{LOD}=$ limit of detection. } \\
\hline $\begin{array}{l}2 \text { H. illucens: initial/larval } \\
{ }^{3} \text { T. molitor: initial/larval } \\
{ }^{4} \text { A. diaperinus: initial/lar } \\
{ }^{5} \text { A. domesticus: initial/la }\end{array}$ & $\begin{array}{l}\text { oncentration. } \\
\text { ncentration. } \\
\text { al concentration. } \\
\text { al concentration. }\end{array}$ & Ilmit of detection. & & \\
\hline
\end{tabular}

limit $(0.10 \mu \mathrm{g} / \mathrm{kg})$ of the analytical methods used (Table 4). However, T. molitor larvae fed with the same spiked substrate contained up to $1.44 \mu \mathrm{g} / \mathrm{kg}$ of AFB1, which is about $10 \%$ of the EU's legal limit for feed materials (Bosch et al., 2017).

None of the considered mycotoxins, as presented in Table 4, accumulated in the insect species considered. H. illucens, T. molitor, and A. diaperinus were fed different substrates at varying concentrations of mycotoxins, with several being well above the EC legal limit for the maximum presence of the particular toxin in feed materials (EC, 2003). For example, Camenzuli and co-authors (Camenzuli et al., 2018) fed $A$. diaperinus and $H$. illucens a wheat-based substrate contaminated with $390 \mu \mathrm{g} / \mathrm{kg}$ AFB1, which is 20 times the EC legal limit for AFB1 in feed materials. Not all combinations of mycotoxins and different insect species have been investigated. Based on results of studies performed so far, accumulation of mycotoxins is not expected in insects. However, this needs to be confirmed in future studies involving the species that have not been investigated so far, such as A. domesticus, L. migratoria, and $M$. domestica.

Even though mycotoxins were seldom found in the insect body, they were regularly found in the residues from excretion throughout these studies. Signifying, bio- transformation of the mycotoxins was reported, resulting in varying levels of metabolites. For example, in a study in which $T$. molitor were fed with $79.9 \mu \mathrm{g} / \mathrm{kg} \mathrm{ZEN}$, the residual materials was found to contain $26.2 \mu \mathrm{g} / \mathrm{kg}$ ZEN, $6.8 \mu \mathrm{g} / \mathrm{kg}$ $\alpha$-ZEL, and $17.3 \mu \mathrm{g} / \mathrm{kg} \beta$-ZEL (Niermans et al., 2019). In addition, when $H$. illucens were fed with $698 \mu \mathrm{g} / \mathrm{kg}$ DON, it resulted in $1,136 \mu \mathrm{g} / \mathrm{kg}$ DON found in the residual materials after excretion. This could be due to masked mycotoxins, which means that the mycotoxins could be bound to a carbohydrate or protein matrix (Purschke et al., 2017). Recently, several studies on the conversion of mycotoxins with phase I and II enzymes have been performed (Meijer et al., 2019). Additional studies of processes of different phase I and II enzymes regarding mycotoxin conversion are recommended to further unravel transformation of mycotoxins by insects.

\section{Plant toxins}

Plant toxins is referred to as the collective group of secondary metabolites in plants which have toxicological properties. The most known plant toxins include cyanogenic glycosides and alkaloids. Cyanogenic glycosides can release hydrogen cyanide when chewed or digested. Alkaloids in plants are nitrogen storage compounds that are involved to protect them against predators, function as growth 
regulators, and substitutes for minerals like potassium and calcium. Plants naturally synthesise alkaloid compounds based on their needs. Some of the synthesised alkaloids like pyrrolizidine, indolizidine, piperidine, and tropane alkaloids have been documented to cause toxic effects on animals and humans (Schramm et al., 2019). Macel (2011) cites older studies that report that several insect species sequester Pyrrolizidine Alkaloids for their own defence, and that concentrations of these compounds in insects can exceed concentrations in the plant, from which they feed. The insect species currently being reared for food or feed are not known to exhibit this behaviour in the live stage in which they are harvested (EFSA, 2015). Bioaccumulation of plant toxins from substrates in insects for feed and food has, however, not been investigated so far.

\section{Conclusions and recommendations}

This review provides recent information on the chemical safety of insects reared for feed and food use, primarily focusing on accumulation of contaminants from substrates into reared insects. Generally, available data are fragmented over a wide range of contaminants and insect species, with most data collected for $H$. illucens and T. molitor. Factors related to the rearing phase, such as insect species, life stage, and source of the contaminant (spiked or naturally contaminated) were confirmed to affect the accumulation of contaminants in insects. Our results showed that, in addition, aspects related to the experimental setting may play a role, as well as the substrate type.

For most contaminants for which experimental data has been collected, an effect on growth and survival of insects was not observed, except for veterinary drugs and pesticides, which may lead to undesirable production effects. Bioaccumulation of some contaminants including the heavy metals, cadmium and lead can occur, and differences between species in accumulation have been observed. Dioxins and dl-PCBs and plant toxins could also potentially accumulate in insects but limited or no data, depending on the insect species, are available for these contaminants. Accumulation of mycotoxins and PAHs has not been observed so far, though, data on the later compound group are very limited. Further research is, therefore, recommended on possible accumulation of plant toxins, dioxins and dl-PCBs, and PAHs from substrates into insects. Furthermore, research on metabolic pathways of mycotoxins and veterinary drugs in insects, regarding possible detoxification/bioactivation pathways is recommended to unravel underlying mechanisms.

\section{Acknowledgements}

This project has received funding from the European Union's Horizon 2020 research and innovation programme under grant agreement No 861976. Additional financing from the Netherlands Ministry of Agriculture, Nature and Food Quality (Knowledge base program KB34, project KB-34-006-001) is acknowledged.

\section{Conflicts of interest}

The authors declare no conflict of interest.

\section{References}

Berntssen, M.H.G., Ørnsrud, R., Hamre, K. and Lie, K.K., 2015. Polyaromatic hydrocarbons in aquafeeds, source, effects and potential implications for vitamin status of farmed fish species: a review. Aquaculture Nutrition 21: 257-273. https://doi.org/10.1111/ anu. 12309

Biancarosa, I., Liland, N.S., Biemans, D., Araujo, P., Bruckner, C.G., Waagbø, R., Torstensen, B.E., Lock, E.-J. and Amlund, H., 2018. Uptake of heavy metals and arsenic in black soldier fly (Hermetia illucens) larvae grown on seaweed-enriched media. Journal of the Science of Food and Agriculture 98: 2176-2183. https://doi. org/10.1002/jsfa.8702

Bordiean, A., Krzyżaniak, M., Stolarski, M.J., Czachorowski, S. and Peni, D., 2020. Will yellow mealworm become a source of safe proteins for Europe? Agriculture 10: 1-30. https://doi.org/10.3390/ agriculture 10060233

Bosch, G., Van der Fels-Klerx, H.J., De Rijk, T.C. and Oonincx, D.G.A.B., 2017. Aflatoxin $B_{1}$ tolerance and accumulation in black soldier fly larvae (Hermetia illucens) and yellow mealworms (Tenebrio molitor). Toxins 9: 185. https://doi.org/10.3390/toxins9060185

Cai, M., Hu, R., Zhang, K., Ma, S., Zheng, L., Yu, Z. and Zhang, J., 2018. Resistance of black soldier fly (Diptera: Stratiomyidae) larvae to combined heavy metals and potential application in municipal sewage sludge treatment. Environmental Science and Pollution Research International 25: 1559-1567. https://doi.org/10.1007/ s11356-017-0541-x

Camenzuli, L., Van Dam, R., de Rijk, T., Andriessen, R., Van Schelt, J. and Van der Fels-Klerx, H.J., 2018. Tolerance and excretion of the mycotoxins aflatoxin $\mathrm{B}_{1}$, zearalenone, deoxynivalenol, and ochratoxin A by Alphitobius diaperinus and Hermetia illucens from contaminated substrates. Toxins 10: 91. https://doi.org/10.3390/ toxins 10020091

Charlton, A.J., Dickinson, M., Wakefield, M., Fitches, E., Kenis, M., Han, R., Zhu, F., Kone, N., Grant, M., Devic, E., Bruggeman, G., Prior, R. and Smith, R., 2015. Exploring the chemical safety of fly larvae as a source of protein for animal feed. Journal of Insects as Food and Feed 1: 7-16. https://doi.org/10.3920/JIFF2014.0020

De Paepe, E., Wauters, J., Van Der Borght, M., Claes, J., Huysman, S., Croubels, S. and Vanhaecke, L., 2019. Ultra-high-performance liquid chromatography coupled to quadrupole orbitrap high-resolution mass spectrometry for multi-residue screening of pesticides, (veterinary) drugs and mycotoxins in edible insects. Food Chemistry 293: 187-196. https://doi.org/10.1016/j.foodchem.2019.04.082

EFSA, 2015. Risk profile related to production and consumption of insects as food and feed. EFSA Journal 13(10): 4257. https://doi. org/10.2903/j.efsa.2015.4257 
European Commission (EC), 2001. Regulation (EC) No 999/2001 laying down rules for the prevention, control and eradication of certain transmissible spongiform encephalopathies. Official Journal of the European Communities L 147: 1.

European Commission (EC), 2003. Directive 2002/32/EC of the European Parliament and of the Council of 7 May 2002 on undesirable substances in animal feed. Official Journal of the European Communities L140: 10-22.

European Commission (EC), 2006a. Commission Regulation (EC) No 1881/2006 of 19 December 2006 setting maximum levels for certain contaminants in foodstuffs. Official Journal of the European Communities L70: 1.

European Commission (EC), 2006b. Commission Recommendation (EC) No 576/2006 on the presence of deoxynivalenol, zearalenone, ochratoxin A, T-2 and HT-2 and fumonisins in products intended for animal feeding. Official Journal of the European Communities L 229: 1-3.

European Commission (EC), 2009. Regulation (EC) No 1069/2009 laying down health rules as regards animal by-products and derived products not intended for human consumption and repealing Regulation (EC) No 1774/2002 (Animal by-products Regulation). Official Journal of the European Communities L 300: 1.

European Commission (EC), 2011a. Commission Regulation (EU) No 142/2011 implementing Regulation (EC) No 1069/2009 of the European Parliament and of the Council laying down health rules as regards animal by-products and derived products not intended for human consumption and implementing Council Directive 97/78/ $\mathrm{EC}$ as regards certain samples and items exempt from veterinary checks at the border under that Directive. Official Journal of the European Union L 54: 1.

European Commission (EC), 2011b. Commission Regulation (EU) No 574/2011 of 16 June 2011 amending Annex I to Directive 2002/32/ EC of the European Parliament and of the Council as regards maximum levels for nitrite, melamine, Ambrosia spp. and carryover of certain coccidiostats and histomonostats and consolidating Annexes I and II thereto. Official Journal of the European Union L 159: 7.

European Commission (EC), 2015a. Regulation (EU) 2015/2283 on novel foods, amending Regulation (EU) No 1169/2011 of the European Parliament and of the Council and repealing Regulation (EC) No 258/97 of the European Parliament and of the Council and Commission Regulation (EC) No 1852/2001. Official Journal of the European Union L 327: 1

European Commission (EC), 2015b. Summary of applications and notifications. European Commission, Brussels, Belgium. Available at: https://tinyurl.com/y25se4or.

European Commission (EC), 2020. Commission Implementing Regulation (EU) 2020/994 of 9 July 2020 concerning the authorisation of monensin and nicarbazin (Monimax) as a feed additive for turkeys for fattening, chickens for fattening and chickens reared for laying (holder of authorisation Huvepharma NV). Official Journal of European Union 221: 79-82.

Fries, G., 1995. A review of the significance of animal food products as potential pathways of human exposures to dioxins. Journal of animal science 73: 1639-1650. https://doi.org/10.2527/1995.7361639x
Gao, M., Lin, Y., Shi, G.-Z., Li, H.-H., Yang, Z.-B., Xu, X.-X., Xian, J.R., Yang, Y.-X. and Cheng, Z., 2019a. Bioaccumulation and health risk assessments of trace elements in housefly (Musca domestica L.) larvae fed with food wastes. Science of the Total Environment 682: 485-493. https://doi.org/10.1016/j.scitotenv.2019.05.182

Gao, Q., Deng, W., Gao, Z., Li, M., Liu, W., Wang, X. and Zhu, F., 2019b. Effect of sulfonamide pollution on the growth of manure management candidate Hermetia illucens. PLoS ONE 14: e0216086. https://doi.org/10.1371/journal.pone.0216086

Gao, Y., Chen, J., Liu, C., Lv, X., Li, J. and Guo, B., 2013. Enantiomerization and enantioselective bioaccumulation of benalaxyl in Tenebrio molitor larvae from wheat bran. Journal of agricultural and food chemistry 61. https://doi.org/10.1021/ jf4020125

Gao, Y., Wang, H., Qin, F., Xu, P., Lv, X., Li, J. and Guo, B., 2014. Enantiomerization and enantioselective bioaccumulation of metalaxyl in Tenebrio molitor larvae. Chirality 26: 88-94.

Gashaw, M., 2016. Review on mycotoxins in feeds: implications to livestock and human health. Journal of Agricultural Research and Development 5: 137-144.

Grau, T., Vilcinskas, A. and Joop, G., 2017. Sustainable farming of the mealworm Tenebrio molitor for the production of food and feed. Zeitschrift fur Naturforschung. Section C, Biosciences 72: 337-349.

Jiang, C., Teng, C., Li, J., Zhu, J., Fen, D., Lou, L. and Zhang, Z., 2017. The effectiveness of bioconversion of food waste by housefly larvae. Chinese Journal of Applied and Environmental Biology 23: 11591165. https://doi.org/10.3724/SP.J.1145.2017.03018

Lalander, C., Senecal, J., Gros Calvo, M., Ahrens, L., Josefsson, S., Wiberg, K. and Vinnerås, B., 2016. Fate of pharmaceuticals and pesticides in fly larvae composting. Science of the Total Environment 565: 279-286. 10.1016/j.scitotenv.2016.04.147

Leni, G., Cirlini, M., Jacobs, J., Depraetere, S., Gianotten, N., Sforza, S. and Dall'Asta, C., 2019. Impact of naturally contaminated substrates on Alphitobius diaperinus and Hermetia illucens: uptake and excretion of mycotoxins. Toxins 11. https://doi.org/10.3390/ toxins 11080476

Li, H., Wan, Q., Zhang, S., Wang, C., Su, S. and Pan, B., 2019. Housefly larvae (Musca domestica) significantly accelerates degradation of monensin by altering the structure and abundance of the associated bacterial community. Ecotoxicology and Environmental Safety 170: 418-426.

Lv, X., Liu, C., Li, Y., Gao, Y., Guo, B., Wang, H. and Li, J., 2013. Bioaccumulation and excretion of enantiomers of myclobutanil in Tenebrio molitor larvae through dietary exposure. Chirality 25: 890-896.

Lv, X., Liu, C., Li, Y., Gao, Y., Wang, H., Li, J. and Guo, B., 2014. Stereoselectivity in bioaccumulation and excretion of epoxiconazole by mealworm beetle (Tenebrio molitor) larvae. Ecotoxicology and environmental safety 107: 71-76.

Macel, M., 2011. Attract and deter: a dual role for pyrrolizidine alkaloids in plant-insect interactions. Phytochemistry Reviews 10: 75-82.

Meijer, N., Stoopen, G., Van der Fels-Klerx, H.J., van Loon, J., Carney, J. and Bosch, G., 2019. Aflatoxin $B_{1}$ conversion by black soldier fly (Hermetia illucens) larval enzyme extracts. Toxins 11: 532. https:// doi.org/10.3390/toxins11090532 
Mlček, J., Adámek, M., Adámková, A., Borkovcová, M., Bednářová, M. and Skácel, J., 2017. Detection of selected heavy metals and micronutrients in edible insect and their dependency on the feed using XRF spectrometry. Potravinarstvo 11(1): 725-730. https:// doi.org/10.5219/850

Mutungi, C., Irungu, F.G., Nduko, J., Mutua, F., Affognon, H., Nakimbugwe, D., Ekesi, S. and Fiaboe, K.K.M., 2019. Postharvest processes of edible insects in Africa: a review of processing methods, and the implications for nutrition, safety and new products development. Critical Reviews in Food Science and Nutrition 59: 276-298. https://doi.org/10.1080/10408398.2017.1365330

Niermans, K., Woyzichovski, J., Kröncke, N., Benning, R. and Maul, R., 2019. Feeding study for the mycotoxin zearalenone in yellow mealworm (Tenebrio molitor) larvae - investigation of biological impact and metabolic conversion. Mycotoxin Research 35. https:// doi.org/10.1007/s12550-019-00346-y

Ochoa Sanabria, C., Hogan, N., Madder, K., Gillott, C., Blakley, B., Reaney, M., Beattie, A. and Buchanan, F., 2019. Yellow mealworm larvae (Tenebrio molitor) fed mycotoxin-contaminated wheat-a possible safe, sustainable protein source for animal feed? Toxins 11. https://doi.org/10.3390/toxins11050282

Oonincx, D.G.A.B., Van Itterbeeck, J., Heetkamp, M.J.W., Van den Brand, H., Van Loon, J.J.A. and Van Huis, A., 2011. An exploration on greenhouse gas and ammonia production by insect species suitable for animal or human consumption. PLoS ONE 5: e14445. https://doi.org/10.1371/journal.pone.0014445

Pius, C., Sichilongo, K., Koosaletse Mswela, P. and Dikinya, O., 2019. Monitoring polychlorinated dibenzo-p-dioxins/dibenzofurans and dioxin-like polychlorinated biphenyls in Africa since the implementation of the Stockholm Convention - an overview. Environmental Science and Pollution Research 26: 101-113. https:// doi.org/10.1007/s11356-018-3629-z

Poma, G., Cuykx, M., Amato, E., Calaprice, C., Focant, J.F. and Covaci, A., 2017. Evaluation of hazardous chemicals in edible insects and insect-based food intended for human consumption. Food and Chemical Toxicology 100: 70-79. https://doi.org/10.1016/j. fct.2016.12.006

Poma, G., Yin, S., Tang, B., Fujii, Y., Cuykx, M. and Covaci, A., 2019. Occurrence of selected organic contaminants in edible insects and assessment of their chemical safety. Environmental Health Perspectives 127: 127009. https://doi.org/10.1289/ehp5782

Proc, K., Bulak, P., Wiącek, D. and Bieganowski, A., 2020. Hermetia illucens exhibits bioaccumulative potential for 15 different elements - implications for feed and food production. Science of The Total Environment 723: 138125. https://doi.org/10.1016/j. scitotenv.2020.138125

Purschke, B., Scheibelberger, R., Axmann, S., Adler, A. and Jäger, H., 2017. Impact of substrate contamination with mycotoxins, heavy metals and pesticides on the growth performance and composition of black soldier fly larvae (Hermetia illucens) for use in the feed and food value chain. Food Additives and Contaminants Part A 34: 1410-1420. https://doi.org/10.1080/19440049.2017.1299946
Roeder, K.A., Kuriachan, I., Vinson, S.B. and Behmer, S.T., 2010. Evaluation of a microbial inhibitor in artificial diets of a generalist caterpillar, Heliothis virescens. Journal of Insect Science 10: 197. https://doi.org/10.1673/031.010.19701

Rumpold, B.A. and Schlüter, O., 2015. Insect-based protein sources and their potential for human consumption: nutritional composition and processing. Animal Frontiers 5: 20-24. https://doi.org/10.2527/ af.2015-0015

Schmitt, E., Belghit, I., Johansen, J., Leushuis, R., Lock, E.-J., Melsen, D., Ramasamy Shanmugam, R.K., Van Loon, J. and Paul, A., 2019. Growth and safety assessment of feed streams for black soldier fly larvae: a case study with aquaculture sludge. Animals 9: 189. https:// doi.org/10.3390/ani9040189

Schramm, S., Köhler, N. and Rozhon, W., 2019. Pyrrolizidine alkaloids: biosynthesis, biological activities and occurrence in crop plants. Molecules 24: 498. https://doi.org/10.3390/molecules240304.98

Truzzi, C., Annibaldi, A., Girolametti, F., Giovannini, L., Riolo, P., Ruschioni, S., Olivotto, I. and Illuminati, S., 2020. A chemically safe way to produce insect biomass for possible application in feed and food production. International Journal of Environmental Research and Public Health 17(6): 2121. https://doi.org/10.20944/ preprints202003.0056.v1

Truzzi, C., Illuminati, S., Girolametti, F., Antonucci, M., Scarponi, G., Ruschioni, S., Riolo, P. and Annibaldi, A., 2019. Influence of feeding substrates on the presence of toxic metals $(\mathrm{Cd}, \mathrm{Pb}, \mathrm{Ni}, \mathrm{As}, \mathrm{Hg})$ in larvae of Tenebrio molitor: risk assessment for human consumption. International Journal of Environmental Research and Public Health 16(23): 4815. https://doi.org/10.3390/ijerph16234815

Van der Fels-Klerx, H.J., Camenzuli, L., Belluco, S., Meijer, N. and Ricci, A., 2018. Food safety issues related to uses of insects for feeds and foods. Comprehensive Reviews in Food Science and Food Safety 17: 1172-1183. https://doi.org/10.1111/1541-4337.12385

Van der Fels-Klerx, H.J., Camenzuli, L., Van der Lee, M.K. and Oonincx, D.G.A.B., 2016. Uptake of cadmium, lead and arsenic by Tenebrio molitor and Hermetia illucens from contaminated substrates. PLoS ONE 11: e0166186. https://doi.org/10.1371/journal.pone.0166186 Van der Fels-Klerx, H.J., Meijer, N., Nijkamp, M.M., Schmitt, E. and Van Loon, J.J.A., 2020. Chemical food safety of using supermarket returns for rearing black soldier fly larvae (Hermetia illucens) for feed and food. Journal of Insects as Food and Feed 6: 475-488. https://doi.org/10.3920/JIFF2020.0024

Van Huis, A., Itterbeeck, J.V., Klunder, H., Mertens, E., Halloran, A., Muir, G. and Vantomme, P., 2013. Edible insects: future prospects for food and feed security. Food and Agriculture Organization of the United Nations, Rome, Italy.

Varelas, V., 2019. Food wastes as a potential new source for edible insect mass production for food and feed: a review. Fermentation 5: 81. https://doi.org/10.3390/fermentation5030081

Zhang, Z., Shen, J., Wang, H., Liu, M., Wu, L., Ping, F., He, Q., Li, H., Zheng, C. and $\mathrm{Xu}, \mathrm{X}$., 2014. Attenuation of veterinary antibiotics in full-scale vermicomposting of swine manure via the housefly larvae (Musca domestica). Scientific Reports 4: 6844. https://doi. org/10.1038/srep06844 
